九州大学学術情報リポジトリ

Kyushu University Institutional Repository

\title{
Change in Egg Size of Japanese Flounder during One Spawning Season
}

Mihelakakis, Apostolos

Fishery Research Laboratory, Faculty of Agriculture, Kyushu University

Yoshimatsu, Takao

Fishery Research Laboratory, Faculty of Agriculture, Kyushu University

Kitajima, Chikara

Fishery Research Laboratory, Faculty of Agriculture, Kyushu University

https://doi.org/10.5109/24093

出版情報: 九州大学大学院農学研究院紀要. 40 (1/2)，pp.53-59，1995-12. Kyushu University バージョン：

権利関係 : 


\title{
Change in Egg Size of Japanese Flounder during One Spawning Season*
}

\author{
Apostolos Mihelakakis, Takao Yoshimatsu \\ and Chikara Kitajima
}

Fishery Research Laboratory, Faculty of Agriculture, Kyushu University, Tsuyazaki, Fukuoka 81 1-33, Japan (Receined July 10, 1995)

\begin{abstract}
Spawning of Japanese flounder Paralichthysolivaceus in captivity was studied at ambient temperature and photo period in one spawning season. The broodstock consisted of five groups of one female and two males each. The spawning lasted 113 days from February 18 to June 10 during which temperature ranged from 9.1 to $19.8^{\circ} \mathrm{C}$. The spawning period and the date of first spawning differed among females. The proportion of viable eggs collected during the spawning season varied among females from 6.6 to $29.3 \%$. Mean egg diameter ranged from 0.757 to 0.986 $\mathrm{mm}$ and tended to decline during the spawning season. Egg diameter was negatively correlated with the time from the commencement of spawning and the water temperature at spawning.
\end{abstract}

\section{INTRODUCTION}

The Japanese flounder Paralichthys olivaceus is found in a wide area from the Kuril Islands and Karafuto to Hongkong. It lives in rather deep waters during the winter time, but from February to June it migrates to shallower waters, about $20 \mathrm{~m}$ deep, for spawning (Okada, 1966). Among pleuronectiformes, this flounder is the most highly prized food fish in Japan and has a commercial value almost equivalent to that of red sea bream Pagrus major.

Hatchery reared flounder have been reported to spawn in captivity from the age of 2 years with manipulation of water temperature and/or photo period (Ijima et al., 1986; Min, 1988; Tsujigado et al., 1989) as well as at ambient temperature and photo period (Tsujigado et al ., 1989). Spawning without hormonal induction or manipulation of temperature and photo period may start from late January to February at a temperature around $10^{\circ} \mathrm{C}$ and generally ceases in April to May when the temperature rises above $20^{\circ} \mathrm{C}$, in Kyushu.

Several authors have related egg size of marine fish to the size of the newly hatched larvae and the growth and activity of the larvae until the start of exogenous feeding (Blaxter and Hempel, 1963; Hunter, 1981; Knutsen and Tilseth, 1985). Most published works regarding spawning of flounder in captivity include data on spawning period, egg production and egg quality. Few published data exist on the spawning of individual flounder at ambient temperature and photo period (Hirano and Yamamoto, 1992). No data are available on the variability in the size of eggs of individual females throughout the spawning season.

The purpose of the present study was to determine the spawning period and

* Contribution from Fish. Res. Lab., Kyushu University, No. 200. 
spawning periodicity of individual females; to monitor the egg size of different batches and to ascertain if individual flounder show a seasonal variation in egg-size; to investigate the egg quality.

\section{MATERIALS AND METHODS}

This study was carried out at the Fishery Research Laboratory of Kyushu University situated in the northern part of Kyushu Island, Japan, in 1993. The fish used were hatched and raised at the same laboratory and belonged to a group of about 40 individuals, 4 or 5 years old. The group was maintained in an outdoor circular concrete tank of $20 \mathrm{~m}^{3}$ water capacity, under ambient conditions of photo period and temperature. From the beginning of February daily observations were made on the tank to identify eggs liberated by females. On 17 February, when the first eggs were found, five females and ten males were selected, measured and weighed. Females had distinct signs of ovarian swelling and males were examined for normal milt release by stripping. Five groups (named A, B, C, D and E), consisting of one female and two males each, were separated and transferred into outdoor concrete circular tanks. Groups A, B and C were put into tanks of $3 \mathrm{~m}^{3}$ water capacity (diameter $=1.8 \mathrm{~m}$; water depth $=1.2 \mathrm{~m}$ ) and groups $\mathrm{D}$ and $\mathrm{E}$ into tanks of $2 \mathrm{~m}^{3}$ capacity (diameter: $1.6 \mathrm{~m}$; water depth: $1.0 \mathrm{~m}$ ). Direct sunlight was intercepted by a roof situated about $3.0 \mathrm{~m}$ above the surface of the tanks. A continuous flow of sand-filtered sea-water (ca. 32 in salinity) was supplied to the tanks at a rate of about $40 \mathrm{l} / \mathrm{min}$. Vigorous aeration was provided through diffuser stones. Moist pellets whose main stuff were brown fish meal and raw mackerel were offered ad libitum once daily. Water temperature was monitored daily to the nearest $0.2^{\circ} \mathrm{C}$.

To collect the eggs released daily, an egg-collecting net was fixed under the outlet pipe outside the spawning tanks. The net was fixed every day in the evening at 16:00 and was removed the next day between 10:00 and 11:00 as long as fish continued to spawn eggs. The amounts of buoyant and sunken eggs were estimated volumetrically using the mean number per aliquot. A sample of an average 100 buoyant eggs was used to estimate the fertilization rate and the proportion of eggs that appeared to be developed abnormally. The eggs were classed as viable if they were buoyant, fertilized and appeared to be developing normally. Egg size was determined by measuring the diameter of 50 buoyant eggs to the nearest $0.001 \mathrm{~mm}$ by using a microscope with a calibrated eye-piece. The mean egg diameters obtained from each batch of all the females recorded during the spawning period were tested for a statistical difference using the student $t$-test.

\section{RESULTS}

\section{Duration and periodicity of spawning}

The commencement of spawning occurred at 12.2\%. Spawning season lasted 113 days from February 18 to June 10. During this period the water temperature fluctuated from 9.1 to $19.8^{\circ} \mathrm{C}$ (Fig. 1). Spawning ceased when temperature had risen to $21.0^{\circ} \mathrm{C}$.

All the females produced eggs and their spawning data are summarized in Table 1. 


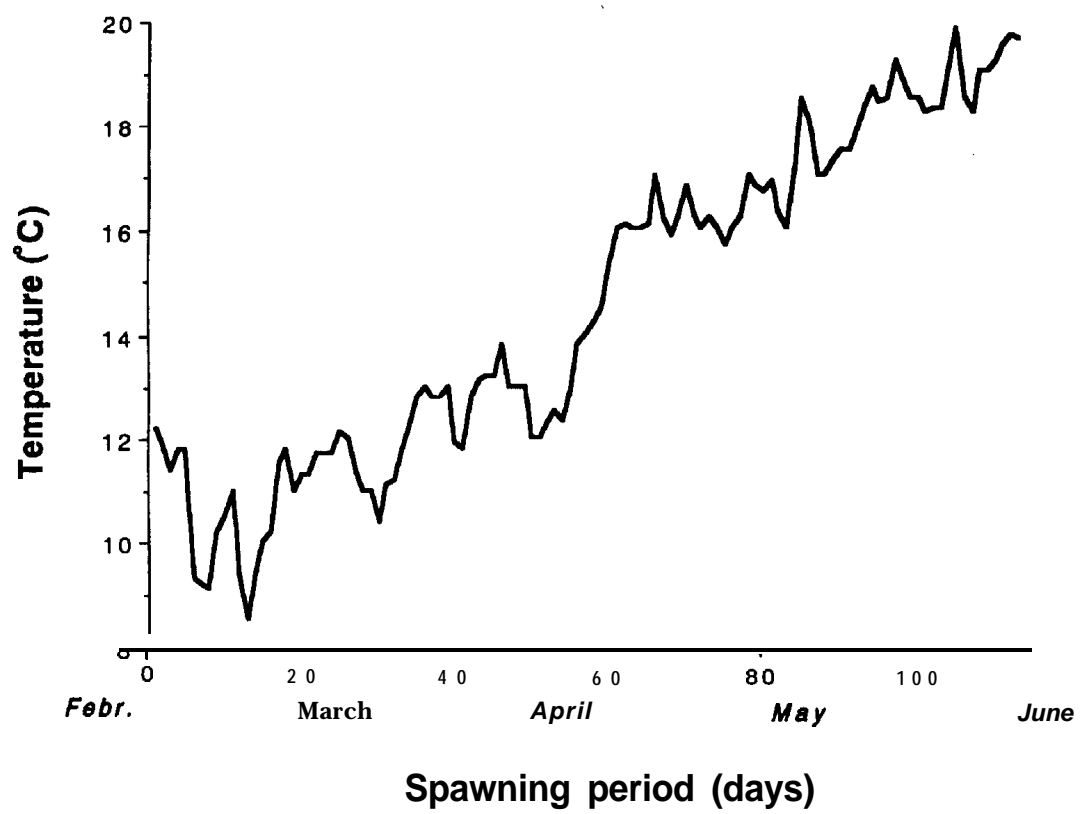

Fig. 1. Water temperature during the spawning season

Table 1. Summary of spawning data for five female P. olivaceus in captivity.

\begin{tabular}{lccccc}
\hline & \multicolumn{5}{c}{ Female } \\
& A & B & C & D & E \\
\hline Body weight $(\mathrm{g})$ & 1380 & 1610 & $\mathbf{1 5 4 0}$ & 1540 & 1260 \\
Total length (cm) & 48.0 & 50.0 & $\mathbf{4 8 . 2}$ & 50.5 & 47.0 \\
Date of first spawning & 11 April & 18 Feb. & $\mathbf{2 4 ~ F e b}$ & 28 March & 20 Feb. \\
Date of last spawning & 10 June & 21 April & 29 May & 24 April & 16 April \\
Spawning period (days) & 61 & 63 & 95 & 28 & 56 \\
Number of batches & 53 & 26 & 23 & 19 & 16 \\
Rate of buoyant eggs $(\%) *$ & 29.9 & 18.9 & 6.8 & 21.7 & 27.5 \\
Rate of viable eggs $(\%)^{*}$ & 29.3 & 18.5 & 6.6 & 21.5 & 27.0 \\
\hline
\end{tabular}

* Percentage from 100 eggs

Individual spawning period varied considerably between females from 28 to 95 days. There was little difference in the spawning periods of females B and E. Females B, C and $\mathrm{E}$ began to spawn in the latter half of February while female D began to spawn more than a month later. Female A had the latest onset of spawning on April 11 (53 days later than the onset of B) and released 53 batches of eggs during a 61-day spawning period. The rest of the females released a considerably smaller number of batches varying from 16 to 26. 


\section{Egg quality}

The fertilization rate of the buoyant eggs of all the females was almost $100 \%$ with exception of the first 2-4 batches of females B, E and $\mathrm{C}$ which had low rates varying from 3 to $9 \%$. The percentage of the buoyant normally developed eggs was high, fluctuating between 96 to $100 \%$. The proportion of buoyant eggs collected during the spawning season varied among females from 6.8 to $29.9 \%$ while the proportion of viable eggs varied from 6.6 to $29.3 \%$ (Table 1 ).

\section{Changes in the size of eggs}

Mean egg diameters of individual females were negatively correlated with the time from the commencement of spawning (Fig. 2). There was a tendency for the size of the

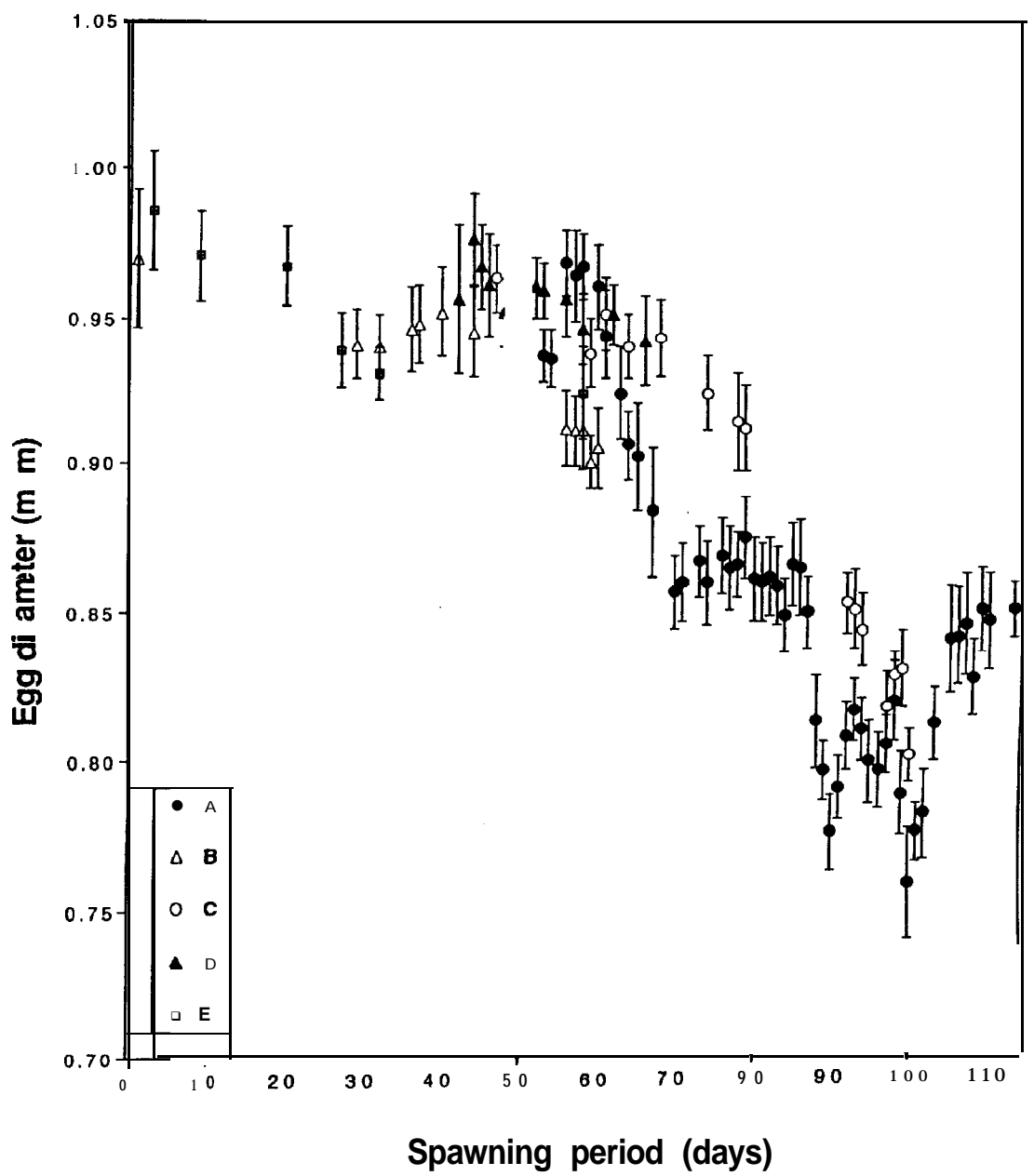

Fig. 2. Relationship between mean egg diameters and time in days from the commencement of spawning. 


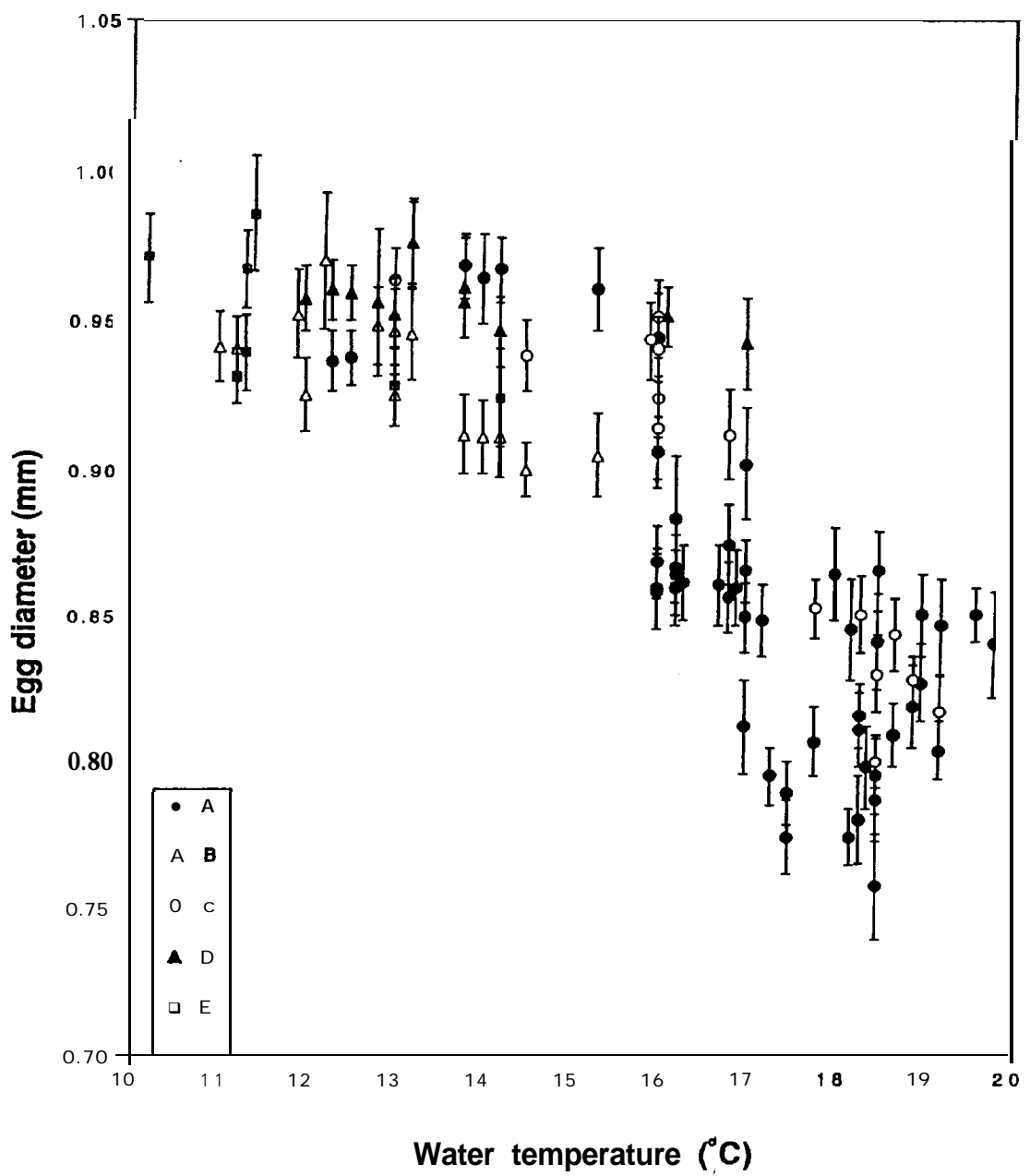

Fig. 3. Relationship between mean egg diameter and water temperature at spawning.

Table 2. Summary of egg diameters for five female P.olivaceus spawned in one spawning season and their level of significance.

\begin{tabular}{cccc}
\hline & \multicolumn{3}{c}{ Egg diameter $(\mathrm{mm})^{*}$} \\
Fynn & maxium & minimum & \\
A & $0.968 \pm 0.011$ & $0.757 \pm 0.018$ & $p<0.001$ \\
B & $0.970 \pm 0.023$ & $0.900 \pm 0.009$ & $p<0.001$ \\
C & $0.963 \pm 0.011$ & $0.800 \pm 0.009$ & $p<0.001$ \\
D & $0.976 \pm 0.015$ & $0.942 \pm 0.015$ & $p<0.001$ \\
E & $0.986 \pm 0.020$ & $0.924 \pm 0.016$ & $p<0.001$ \\
\hline
\end{tabular}

* Mean diameter of 50 eggs obtained from each batch. Mean \pm SD 
eggs to decrease as the spawning season progressed. Since water temperature increased during the spawning period, there was also a negative correlation between the egg size and temperature at spawning (Fig. 3). The mean egg diameter produced over the whole spawning season among females ranged from 0.854 to $0.954 \mathrm{~mm}$. On the other hand, maximum value in diameter ranged from 0.963 to $0.986 \mathrm{~mm}$ and minimum value in diameter ranged from 0.757 to $0.942 \mathrm{~mm}$. The maximum and minimum values of egg diameters from all the females were significantly different $(p<0.001$, Table 2). Female A showed the greatest decline in egg diameter $(21.8 \%)$.

\section{DISCUSSION}

The results of this study indicate that under natural fluctuations of water temperature and photo period the spawning period of individual flounder may vary within a single season, and a female can have a prolonged spawning lasting up to three months.

The percentage of the sinking eggs over the whole spawning period varied among females from 70.1 to $93.2 \%$. Tsujigado $e t$ al . (1989) observed that from two groups of spawners the rates of buoyant eggs were $29.7 \%$ and $32.2 \%$. Also, Hirano and Yamamoto (1992) reported that from five groups of spawners, each consisting of one female and three males, the rates of buoyant eggs varied from 16.2 to $32.9 \%$ and the fertilization rates of the buoyant eggs were law, varying from 29.3 to $53.1 \%$ respectively. These proportions of buoyant eggs are generally of the same level as found in the present study (with exception female C). Over-ripening of eggs inside the ovary has been recognized as a possible major cause of poor quality egg batches in captive broodstocks (Nomura et al., 1974; Sakai et al., 1975; McEvoy, 1984). Bromley et al. (1986) suggested that stress, sperm quality and damage to the eggs during collection might contribute to the production of non-viable eggs. The nutritional quality of broodstock diets has been also proved to be an important factor (Watanabe et al., 1984).

The present study confirms that average egg diameter of individual flounder females changes from batch to batch and the egg size may differ considerably with spawning period. In addition, egg size generally declines as the spawning season progresses along with a rising of water temperature. The decline of egg size over a period in which the temperature is rising has been also observed in individual marine fish spawned "naturally" in captivity such as in red sea bream (Matsuura et al., 1988) and in silver sea bream, Spar-us sarba (Lin et al., 1990), as well as in hand-stripped fish such as in turbot, Scophthalmus maximus (Howell and Scott, 1989). The reason for this size decline is still unclear. Bromley et al. (1986) suggested that temperature at the time of spawning may have a direct influence on egg size and Devauchelle et al. (1987) that the variation in egg diameter should be a consequence of events closer to oviposition. McEvoy and McEvoy (1991) studied the size fluctuation in the eggs of captive turbot, under constant temperature prior to and throughout their spawning season, and suggested that the observed decline of the egg size would have to be genetically controlled.

Further information on the fecundity and spawning periodicity of individual flounder are needed, by studying a large number of females. It would also be of great interest to investigate the effects of egg size on larval size and the survival of larvae during the 
transition period from yolk-sac to exogenous feeding.

\section{REFERENCES}

Blaxter, J., and G. Hempel 1963 The influence of egg size on herring larvae (Clupeaharengus L.). $J$ Cons. Int. Explor. Mer, 28: 211-240

Bromley, P. J., P. A. Sykes and B. R. Howell 1986 Egg production of turbot (Scophthalmus maximus L.) spawning in tank conditions. Aquaculture, 53: 287- 293

Devauchelle, N., J. C. Alexandre, N. Le Corre and Y. Letty 1987 Spawning of sole (Solea solea) in captivity. Aquaculture, 66: 125-147

Hirano, R. and E. Yamamoto 1992 Spawning rhythm and egg number at the individual female spawning experiment in the hirame flounder, Paralichthysolivaceus. Bull. Tottori Pref. Fish.Exp. Station, 33: $18-28$

Howell, B. R. and A. P. Scott 1989 Ovulation cycles and post-ovulatory deterioration of eggs of the turbot (Scophthalmusmaximus L. ). Rapp. P.-1. Reun. Cons. int. Explor: Mer, 191: 21-26

Hunter, J. R. 1981 Feeding ecology and predation of marine fish larvae. In "Marine Fish Larvae, Morphology, Ecology and Relation to Fisheries", ed. by R. Lasker, University of Washington Press, Seattle, WA, USA, pp. 33-77

Ijima, T., T. Abe, R. Hirakawa and Y. Torishima 1986 Early spawning of Japanese flounder Paralichthys ohvere?us with elongated day treatment. Saibai-giken, 15: 57-62

Knutsen, G. M. and S. Tilseth 1985 Growth, development, and feeding success of Atlantic cod larvae Gadus morluua related to egg size. Trans. Am. Fish. Soc., 114: 507-511

Lin, K. J., J. Y. Tn-u and C. H. Chen 1990 Studies of daily spawning and quality of eggs in one goldline sea bream, Sparus sarba. Bull. Taiman Fish Res. Inst., 48: 251-262

McEvoy, L.A. 1984 Ovulatory rhythms and overripening of eggs in cultivated turbot, Scophthalmus maximus L. J. Fish Bid., 24: 437-448

McEvoy, L.A. and J. McEvoy 1991 Size fluctuation in the eggs and newly hatched larvae of captive turbot (Scophthalmus maximus). J. Mar. Biol. Assoc. U.K., 71: 679-690

Matsuura, S., M. Furuichi, K. Maruyama and M. Matsuyama 1988 Daily spawning and quality of eggs in one female red sea bream Pagrusmajor. Suisanzoshoku, 36: 33-39

Min, B. S. 1988 Maturation and spawning of flounder (Paralichthysoliwaceus) under captive conditions. Aquaculture, 1: 25-39

Nomura, M., K. Sakai and F. Takashima 1974 The over-ripening phenomenon of rainbow trout - I. Temporal morphological changes of eggs retained in the body cavity after ovulation. Nippon Suisan Gakkaishi., 40: 977-984

Okada, Y. 1966 Fishes of Japan. Uno Shoten, Tokyo, p. 392

Sakai, K., M. Nomura, F. Takashima and H. Oto 1975 The over-ripening phenomenon of rainbow trout -II. Changes in the percentage of eyed eggs, hatching rate and incidence of abnormal alevins during the process of over-ripening. Nippon Suisan Gakkaishi, 41: 855-860

Tsujigado, A., T. Yamakawa, H. Matsuda and N. Kamiya 1989 Advanced spawning of the flounder, Paralichthysolivaceus, in an indoor tank with combined manipulation of water temperature and photoperiod. Int. J.Aq.Fish.Technol., 1: 351-356

Watanabe, T., T. Arakawa, C. Kitajima and S. Fujita 1984 Effect of nutritional quality of broodstock diets on reproduction of red sea bream. Nippon Suisan Gakkaishi, 50: 495-501 